\title{
Commentary
}

\section{Building on the Past, Shaping the Future: The Environmental Mutagenesis and Genomics Society}

\author{
Thomas E. Wilson, ${ }^{1 *}$ David M. DeMarini, ${ }^{2}$ Stephen D. Dertinger, ${ }^{3}$ \\ Bevin P. Engelward, ${ }^{4}$ Philip C. Hanawalt, ${ }^{5}$ James T. MacGregor, ${ }^{6}$ \\ Stephanie L. Smith-Roe, ${ }^{7}$ Kristine L. Witt, ${ }^{7}$ Carole L. Yauk, ${ }^{8}$ \\ Mats Liungman, ${ }^{\text {Jeffrey L. Schwartz, }}{ }^{10}$ and Catherine B. Klein ${ }^{11}$ \\ ${ }^{1}$ Departments of Pathology and Human Genetics, University of Michigan \\ Medical School, Ann Arbor, Michigan \\ ${ }^{2}$ Integrated Systems Toxicology Division, U.S. Environmental Protection Agency, \\ Research Triangle Park, North Carolina \\ ${ }^{3}$ Litron Laboratories, Rochester, New York \\ ${ }^{4}$ Department of Biological Engineering, Massachusetts Institute of Technology, \\ Cambridge, Massachusetts \\ ${ }^{5}$ Department of Biology, Stanford University, Stanford, California \\ ${ }^{6}$ Toxicology Consulting Services, Bonita Springs, Florida \\ ${ }^{7}$ Division of the National Toxicology Program, NIEHS, Research Triangle Park, \\ North Carolina \\ ${ }^{8}$ Environmental Health Science and Research Bureau, Health Canada, Ottawa, \\ Ontario \\ ${ }^{9}$ Department of Radiation Oncology and Translational Oncology Program, \\ University of Michigan Medical School, Ann Arbor, Michigan \\ ${ }^{10}$ Department of Radiation Oncology, University of Washington Medical \\ School, Seattle, Washington \\ ${ }^{11}$ Department of Environmental Medicine, NYU School of Medicine, \\ Tuxedo, New York
}

\begin{abstract}
In late 2012, the members of the Environmental Mutagen Society voted to change its name to the Environmental Mutagenesis and Genomics Society. Here, we describe the thought process that led to adoption of the new name, which both respects the rich history of a Society

founded in 1969 and reflects the many advances in our understanding of the nature and breadth of gene-environment interactions during the intervening 43 years. Environ. Mol. Mutagen. 54:153-157, 2013. (c) 2013 Wiley Periodicals, Inc.
\end{abstract}

\section{HISTORICAL FOUNDATION}

A detailed history of the Environmental Mutagen Society (EMS) has been recounted previously [Wassom, 1989; Wassom et al., 2010]. The EMS was founded in 1969 by a group of distinguished scientists that included Alexander Hollaender, Joshua Lederberg, James Crow, James Neel, William Russell, Heinrich Malling, Frederick J. de Serres, and Matthew Meselson (www.emgs-us.org). The goals and interests of the Society were and are to promote research and training of scientists in the fields of environmental mutagenesis and genetic toxicology to promote human health by minimizing exposure risks.
Additional Supporting Information may be found in the online version of this article.

*Correspondence to: Thomas E. Wilson, Department of Pathology, University of Michigan Medical School, 2065 BSRB, 109 Zina Pitcher Place, Ann Arbor, MI 48109-2200, USA.

E-mail: wilsonte@umich.edu

Received 11 January 2013; provisionally accepted 16 January 2013; and in final form 16 January 2013

DOI 10.1002/em.21765

Published online 26 February 2013 in

Wiley Online Library (wileyonlinelibrary.com). 
As a vibrant community of scientists, EMS proved to be fertile ground that quickly connected and expanded member efforts. A growing emphasis on policy led to a key 1975 position article that highlighted the regulatory responsibility of government to identify potential mutagens before they are introduced into the environment [EMS Committee 17, 1975]. These and other member actions helped to establish the Toxic Substances Control Act of 1976, which empowered the United States Environmental Protection Agency (EPA) to include mutagenicity data in regulatory decisions and served as a model for similar legislation worldwide [Hollaender and de Serres, 1978; U.S. EPA, 2010]. Attendant needs for uniform testing methods and interpretations led to the seminal book series "Chemical Mutagens: Principles and Methods for Their Detection" [Hollaender, 1971] that included the first article published on the Ames Salmonella mutagenicity assay [Ames, 1971]. Cuttingedge efforts in genetic toxicology, including computational toxicology, toxicogenomics, and high-throughput screening, continue to the current day.

In parallel with regulatory and testing efforts, EMS has always been driven by research into the basic mechanisms of action of mutagens and their many varied effects on organismal biology and human health [Wassom et al., 2010]. Although initial interests centered on germline mutagenesis, the importance of somatic mutations to the pathogenesis of cancer was soon appreciated. Increased understanding of DNA, its chemistry and encoded information, and the many processes that manipulate and repair that information, collectively known as "molecular biology," led to more precise explorations of mutational mechanisms and, ultimately, a renaming of the Society's journal in 1987 from its original 1979 title "Environmental Mutagenesis" to "Environmental and Molecular Mutagenesis" [Hoffmann, 1987, 2004]. In a continued progression of scientific insight and thought, members are now strongly engaged in consideration of not only the genetic but also the epigenetic and genomelevel responses to environmental agents.

\section{MOTIVATION FOR CHANGE}

Throughout its dynamic history, the name of the Society has remained singular and constant. To be sure, members consistently value the connection of the EMS name with the roots highlighted above. Nevertheless, in various forums over recent years, many members expressed the belief that the words EMS did not capture a strong focus on mechanism nor the more modern sensibilities engendered by continued scientific insights into the nature of gene-environment interactions. Similar discussions were occurring within the International Association of Environmental Mutagen Societies (IAEMS), leading to a position article that argued for a change in name [DeMarini and
De Flora, 2010]. The Society name was the focus of a well-attended "Town Hall Meeting" at the 42nd EMS Annual Meeting in 2011 in Montreal, Canada. The broad interest and strong opinions of the attendees led to the establishment of a Task Force to address the name change issue through a more formal process.

\section{BRAND IDENTITY TASK FORCE}

The EMS Brand Identity Task Force was comprised of active Society members representing a diversity of demographics, scientific interests, and opinions on the name issue. Its scope was broadly defined as all mechanisms used by the Society to communicate and advertise our mission and activities, including but not limited to the Society name. The Task Force restricted its activities to the North American EMS, the membership base we represented, but we were mindful that our actions were of potential interest to the international community. The Task Force had the following specific objectives: (i) to establish a database of member opinions and input on important brand identity issues, (ii) to identify and build membership consensus on the Society's mission, and (iii) to use the assembled information to generate specific and actionable recommendations to the Society. Retaining the EMS name was understood to be one of the possible recommendations.

\section{MEMBERSHIP SURVEY}

To achieve its objectives, the Task Force conducted an internet survey that presented a series of unbiased questions regarding the intellectual concepts that define the Society (Supporting Information 1). For all items, alternative viewpoints were provided based on previously voiced opinions. In addition to these ranked-response items, respondents were invited to make comments and suggestions. In total 151 people responded, approximately one-third of the active EMS membership (Supporting Information 2). Respondents represented each of the various demographic groups within the Society, and there was no apparent stratification of responses by any demographic parameter, including scientific discipline, occupational setting (government, academia, and industry), and age. Thus, survey data were considered strongly representative of the opinions of the Society as a whole.

The three most highly ranked brand concepts were "mutagenesis," "genetics," and "environment." "Health" was also ranked highly, but enthusiasm was lower for "molecular." "Epigenetics" was considered central to our mission, but with the commonly voiced opinion that it could be considered to be a subset of other concepts. "Mutagenesis" was uniformly positively regarded, although on its own was too confining for individuals 
interested mainly in nonmutagenic/epigenetic changes. Although not queried specifically, comments in the survey and open-forum discussions indicated that "mutagen" was not as appealing to most members as "mutagenesis." Despite the fact that the survey did not specifically ask about "genomics," numerous suggestions included this word, demonstrating that to many it was a strong and modern manifestation of "genetics." "Environment" was strongly supported by most respondents, but a small minority held strongly negative opinions of this concept word, mainly because it might be misinterpreted as only representing flora and nonhuman fauna rather than a factor impacting human health.

Respondents sought to display through our brand an excitement about what makes EMS unique. Recurring themes were the strengths derived from our diversity of interests and backgrounds and that we are a true community of scientists who interact, collaborate, and mutually support each other. Respondents wanted the EMS brand to attract young scientists to encourage them to help define its mission moving forward.

Approximately equal numbers of respondents reported satisfaction and dissatisfaction with the name EMS. This dichotomy of opinions indicated that any consideration of a name change would need to be approached carefully and with full respect to member identification with the existing brand. Nevertheless, a strikingly high percentage of members disliked the EMS name, which even its advocates recognized as problematic. Importantly, comments revealed that many people who expressed satisfaction with the name considered it "good enough" rather than fully optimal. Accordingly, the Task Force believed that most members would be open to an improved name if it could be arrived at quickly, decisively, and through a consensus that strengthened the Society and its mission.

\section{TASK FORCE RECOMMENDATION}

After carefully considering the survey data and other inputs, the Task Force unanimously endorsed Environmental Mutagenesis and Genomics Society (EMGS) as an appropriate and desirable new name for our organization. To understand the deliberations that led to this recommendation, it is useful to restate the mission of the Society as seeking to understand the process (mutagenesis) by which agents (mutagens) derived from a source (the environment) impact a target [the (epi)genome]. The objective of this effort is to promote an outcome (human and ecological health) through appropriate activities (research, oversight, and regulation).

The EMS name encompasses one word, "Environment(al)," which might be considered either a "source" or a "target," and which might therefore engender ambiguity, especially among nonscientists for whom it is often a politically charged concept. Nevertheless, a defining mission of the Society is to understand the effects of the environment, and especially exposure to chemical or physical agents in the environment, on human health and the vitality of natural populations. The Task Force concluded that the Society name must include the word "Environment(al)" but that improving the specificity of its scientific context as "source" was desirable. Once this decision was made, it was clear that the structure "Environmental Society" should also be retained, as it promotes a desirable continuity from past to future. Thus, the further question was whether and how to replace "Mutagen" with more effective descriptor(s).

"Mutagen" is unambiguously an "agent." Emphasis on mutagens made perfect sense in 1969 when the most pressing needs were to understand what harmful agents were present in the environment and to test the central hypothesis that these agents could negatively affect human health via genetic mechanisms. While these needs are certainly not fully satisfied, decades of acquired knowledge allow us to ask questions more robustly with respect to "process" and "target," which in fact encompass most of the current activities of Society members. Our knowledge of DNA repair and other cellular processes, as well as the nature of the genome, including entirely new concepts such as epigenetics, has significantly modified the way we think about our mission. The simple change from "Mutagen" to "Mutagenesis" shifts the emphasis toward "process," while continuing to embrace those who study agents.

Finally, the word "Genomics" was added to identify more richly "target" and to continue to disambiguate "Environmental." The term "Environmental Genomics" has gained broad acceptance in the scientific community in recent years as evidenced by the publication of a book under that title, as well as the establishment of organizational structures including a laboratory at the National Institute of Environmental Health Sciences, university curricula and centers across the globe, and a recent National Science Foundation funding opportunity [Martin, 2008; DeMarini and De Flora, 2010]. Clearly, the term is a modern innovation, which was considered desirable, as it will resonate with the next generation of scientists. Moreover, it accurately describes the Society, which has increasing numbers of members embracing whole (epi) genomic responses as "target". In some uses, the term is tied to specific technologies, but when all factors were considered, it was deemed more important that "genomics" is rapidly becoming a defining keyword of well-grounded scientific disciplines that identify the genome as a fundamental unit of information targeted by environmental influences.

Together, EMGS is a name that more accurately reflects the current scope of scientific investigation in our discipline, while at the same time respects the Society's 
tradition and history. Inclusion of both "Mutagenesis" and "Genomics" conveys important concepts that neither word achieves alone. In pointedly encompassing references to each of "source," "process" and "target," the EMGS name offers connectable concepts to many scientists, including young scientists. It finally disambiguates "Environmental" and changes "Mutagen" to more holistic and broadly recognizable words. The name misses some concepts that are important to the Society's mission, such as "toxicology," "regulatory policy," and "human health," but candidate names that attempted to include all of these diverse concepts were too long and unwieldy. The Task Force suggested that such extended concepts are best incorporated into tagline phrases that could accompany the Society name in print and online media.

\section{VOTING PROCESS}

The EMGS name recommendation and the rationales described above were presented to the EMS Executive Board. After extensive deliberation, the Board voted to proceed with the recommendation by passing it to Council. Council in turn voted to bring the candidate new name to the membership. As a by-laws change, a twothirds majority of voting members was required for the new name to be adopted, otherwise the longstanding EMS name would be retained. This challenging threshold was exceeded, and the name EMGS was officially adopted in December 2012.

\section{PERSPECTIVES}

We are excited about the new directions that the EMGS name embraces. The focus of the Society continues to include studies on the effects of mutagenic and genotoxic agents to which humans and other species are exposed, but it places increased emphasis on the fundamental mechanisms by which genomic instability is generated. The broad term "environmental" encompasses not only chemicals in our air and water but also endogenous agents generated by normal metabolism, organismal age, and stage of development, lifestyle factors such as diet and exercise, and even socioeconomic status. Understanding how biological systems respond to these factors requires thinking on a broad scale, encompassing gene networks, regulation by RNAs, and epigenetic processes. By taking advantage of technological advances in these disciplines, we will be in a position to understand better the ways that the environment continues to shape our genome and to apply the principles we learn to improve health and well-being worldwide.

Scientists who share this vision are invited to join the EMGS and help solve the still pressing health problems related to exposure to extrinsic and intrinsic mutagens (www.emgs-us.org). As a professional home, the Society is dedicated to fostering collegiality that promotes scientific progress through networking and collaboration tools, stimulating annual meetings, support of young investigators, international education courses, and this journal. By bringing together representatives from academia, governmental agencies, and industry, the EMGS is a uniquely diverse community that enables synergy across many scientific disciplines, perspectives, and objectives, thus ensuring that research advances will have maximal impact.

\section{ACKNOWLEDGMENTS}

The authors thank IAEMS President Stefano Bonassi for his initiative in promoting international discussions of the name issue, and they appreciate as well the innumerable members and past leaders of EMGS who have played critical roles in sharing their visions of the Society and the science that they seek to advance. They regret that it is not possible to name them all individually. This manuscript was reviewed by the National Health and Environmental Effects Research Laboratory, the United States Environmental Protection Agency, and the National Institute of Environmental Health Sciences, and was approved for publication. Approval does not signify that the contents reflect the views of either agency or the United States government, nor does mention of trade names or commercial products constitute endorsement or recommendation for use.

\section{AUTHOR CONTRIBUTIONS}

T.E.W. prepared the manuscript and Supporting Information and served as Chair of the Brand Identity Task Force. D.M.D., S.D.D., B.P.E., P.C.H., J.T.M., S.L.S-R., K.L.W., and C.L.Y. served on the Task Force. All Task Force members prepared the survey instrument. D.M.D., S.D.D., B.P.E., P.C.H., J.T.M., S.L.S-R., K.L.W., C.L.Y., M.L., J.L.S., and C.B.K. contributed to the manuscript. D.M.D. initiated international discussions on the name change while serving as IAEMS President in 2005-2009. M.L. is the 2012-2013 EMGS President and presided over the by-laws vote. J.L.S. served as EMS President in 2010-2011 and presided over the Town Hall Meeting that led to formation of the Task Force. C.B.K. served as EMS President in 2011-2012, created the Task Force, and presided over its conduct.

\section{REFERENCES}

Ames BN. 1971. The detection of chemical mutagens with enteric bacteria. In: Hollaender A, editor. Chemical Mutagens: Principles and Methods for Their Detection, Vol. 1. New York: Plenum Press. pp 267-282.

DeMarini DM, De Flora S. 2010. What's in a name? The argument for changing the name of IAEMS and its affiliated societies. Mutat Res 705:201-204. 
EMS Committee 17. 1975. Environmental mutagenic hazards. Science 187:503-514.

Hoffmann GR. 1987. Editorial. Environ Mol Mutagen 10:1.

Hoffmann GR. 2004. History of environmental and molecular mutagenesis. Environ Mol Mutagen 44:352-362.

Hollaender A, editor. 1971. Chemical mutagens: Principles and methods for their detection, Vol 1. New York: Plenum Press.

Hollaender A, de Serres FJ. 1978. Toxic substances control act. In: Hollaender A, editor. Chemical Mutagens: Principles and Methods for Their Detection, Vol. 5. New York: Plenum Press. pp 287335.
Martin CC, editor. 2008. Environmental genomics. In Series: Walker JM, editor. Methods in Molecular Biology, Vol. 410. New Jersey: Humana Press. pp 364.

U.S. Environmental Protection Agency. 2010. Summary of the Toxic Substances Control Act. Available at: http://www.epa.gov/regulations/laws/tsca.html [accessed on 29 December 2012].

Wassom JS. 1989. The origins of genetic toxicology and the Environmental Mutagen Society. Environ Mol Mutagen 14 (Suppl 16):1-6.

Wassom JS, Malling HV, Sankaranarayanan K, Lu P-Y. 2010. Reflections on the origins and evolution of genetic toxicology and the environmental mutagen society. Environ Mol Mutagen 51:746760 . 